\title{
Comparison of Preeclampsia Risk Factors Regarding to Severity with Control Group
}

\author{
Seyedeh Hajar Sharami, ${ }^{1}$ Manoush Zendehdel, ${ }^{2,}$ Fariba Mirblouk, ${ }^{1}$ Maryam Asgharnia, ${ }^{1}$ Roya Faraji, \\ Seyedeh Fatemeh Dalil Heirati, ${ }^{1}$ and Fatemeh Salamat ${ }^{2}$ \\ ${ }^{1}$ Department of Obstetrics and Gynecology, Reproductive Health Research Center, Alzahra Hospital, Guilan University of Medical Sciences, Rasht, Iran \\ ${ }^{2}$ Research vice-chancellorship, Guilan University of Medical Sciences, Rasht, Iran \\ "Corresponding author: Manoush Zendehdel, Research vice-chancellorship, Guilan University of Medical Sciences, Rasht, Iran. Tel: +98-9111379667, E-mail: sepas777@yahoo.com
}

Received 2015 December 09; Revised 2016 April 24; Accepted 2017 January 09.

\begin{abstract}
Background: Preeclampsia is a relatively common pregnancy disorder that originates in the placenta and causes variable maternal and fetal complications.

Objectives: The aim of the study was to investigate risk factors of preeclampsia based on severity.

Methods: This is a cross-sectional study which was conducted on 448 participants (330 normal pregnant, 77mild and 91severe preeclamptic women). Inclusion Criteria were age 15 - 44 years and 20 - 24 weeks of gestation. The data collection form consisted of the kind of pregnancy (normal, mild or sever preeclampsia), BP, U/A, other library tests, demo graphic information, history of obstetrics and diseases. The data were analyzed by ANOVA, POST HOC test (tukey HSD), Chi-square and logistic regression using SPSS version 16.

Results: Finding showed the mean age in the severe preeclampsia group and the mean BMI in mild and severe preeclamptic women were significantly higher than normal group. Also there was significant relationship between preeclampsia and age, BMI, RH, history of abortion, preeclampsia and chronic hypertension. Logistic regression analysis showed that respectively the negative RH and history of preeclampsia increased the risk of severe preeclampsia.

Conclusions: Based on results, chronic hypertension, history of abortion and BMI had been indicated as risk factors of mild preeclampsia and history of preeclampsia had been obtained as the risk factors of severe type. Also, negative RH was the common risk factor for mild and severe types. Therefore, our result support different risk factors for subtypes of preeclampsia.
\end{abstract}

Keywords: Preeclampsia, Risk Factors, High Risk, Abortion, Mild Preeclampsia, Severe Preeclampsia, Hypertension, Proteinuria

\section{Background}

Preeclampsia is a relatively common pregnancy disorder that originates in the placenta and causes variable maternal and fetal complications [1]. In developing countries, the prevalence of preeclampsia ranges between 1.8 to $16.7 \%$ [2] and it is the second leading cause of maternal mortality and morbidity which accounts for $18 \%$ of maternal deaths, worldwide [3]. According to the recent report from ministry of health (2012), 22 per 100000 maternal deaths occurred by preeclampsia in our country [4]. Preeclampsia can be clinically divided in mild and severe types. Since more/severe clinical symptoms, worse maternal and fetal complications, higher risk of eclampsia and development of disease are more associated with the sever type in comparison with mild type of this disorder, some investigators have suggested different pathogenesis and etiologic factors for mild and sever forms of preeclampsia [5]. Previous investigations demonstrated that preeclampsia is a multifactorial disease. They noted that history of preeclampsia; age, diabetes mellitus, chronic hypertension (HTN), nulli parity, previous abortion, increased BMI (body mass index) $[6,7]$, fetal gender [8], migraine [9] and negative maternal $\mathrm{RH}[10]$ could be considered as risk factors for preeclampsia.

Although, in the previous years, investigations have been performed in this field, but Majority of those studies have evaluated risk factors of preeclampsia without considering to severity of disease.

So investigators require to know more about the etiology and pathogenesis of this complicated and recognition weather risk factors of preeclampsia is different regarding to its severity. Because it is very important to prevent the adverse effects of disease and establish a purposeful planning and intervention. Therefore, we aimed to investigate risk factors of preeclampsia based on severity of disease.

\section{Methods}

This is an analytic cross-sectional study which was conducted on 498 pregnant women referred to Midwifery 
Emergencies and Obstetrics Department of Alzahra Hospital, in Rasht. Participants were 168 preeclamptic patients (77 mild and 91 severe) and 330 normal pregnant women. The criteria for the diagnosis of preeclampsia was blood pressure (BP) $\geq 140 / 90 \mathrm{mmHg}$ on two occasions after 30 minutes of rest and proteinuria (300 $\mathrm{mg}$ of protein in a 24 hours urine sample)with no detectable infection in urine analysis (U/A). Severe and mild preeclampsia was defined based on ACOG (American college of obstetrics and gynecology) by the following criteria: $\mathrm{BP} \geq 160 / 110$ on two occasions of at least 6 hours apart, significant proteinuria and clinical symptoms. Inclusion criteria were indicated as maternal age ( 15 - 44 years old), gestational age $\geq 20$ weeks based on LMP (last menstrual period) and ultrasound and normal fetus (by sonography). Also, exclusion criteria were fetal abnormalities, polyhydramnios, gestational trophoblastic diseases and pregnancy by assisted reproductive technologies such as invitro fertilization (IVF). Data were collected by interview and medical records by a form which consisted of the kind of pregnancy (normal, mild or sever preeclampsia), BP, U/A, other library tests, maternal age, parity, BMI, place of inhibitions, occupation, blood group and $\mathrm{RH}$, fetal gender, multiple gestations, history of migraine, diabetes mellitus, chronic hypertension, consanguineous, preeclampsia and urinary tract infection.

\subsection{Statistical Analysis}

Mean, standard deviation, frequency and percentage were used for descriptive statistics and data were analyzed by ANOVA, POST HOC test (tukey HSD) and Chi-square using SPSS version 16. Also, logistic regression was used for probability of preeclampsia. Ninety five percent confidence interval indicated and $\mathrm{P}<0.05$ considered as significant difference.

\section{Results}

Results revealed that preeclamptic women were older than normal ones. Although, there were no significant differences regarding to age between mild preeclamptic group and normal women $(\mathrm{P}>0.05)$, however, results noted significant difference between severe preeclampsia and normal pregnant $(\mathrm{P}=0.003)$. Also, the the mean BMI was significantly different in mild and normal group $(\mathrm{P}=$ $0.001)$ and the severe and normal ones $(P=0.007)$.

Furthermore, there was no significant difference between groups regarding to nulliparity, occupation, and place of inhibitions, consanguineous, fetal gender, multiple gestations, diabetes mellitus, urinary tract infection and birth interval (Table 1 ).

More ever, results revealed significant relationship between preeclampsia and age $(\mathrm{P}=0.008), \mathrm{BMI}(\mathrm{P}=0.0001)$,
RH ( $\mathrm{P}=0.0001)$ history of abortion $(\mathrm{P}=0.019)$, history of preeclampsia $(\mathrm{P}=0.001)$ and chronic $\operatorname{HTN}(\mathrm{P}=0.0001)$.

Logistic regression demonstrated that the risk of preeclampsia in women with the personal history of HTN were more $(\mathrm{OR}=12.33,95 \% \mathrm{CI}=1.99-76.05)$ (and and it distinguishably showed that HTN could only increase the risk of mild preeclampsia $(\mathrm{OR}=13.7,95 \% \mathrm{CI}=3.6-52.14)$.

According to (Table 3), chronic HTN (13.7 times), negative RH (7.94 times) and history of abortion (2.72 times) could increase the risk of mild preeclampsia. Also, the risk of mild preeclampsia could be increased by BMI and there was a direct relationship between them.

In addition, the findings reported Negative RH and history of preeclampsia as the most important variables for developing severe preeclampsia (Table 4) and multi parity has a protective effect against developing mild (OR $=0 / 32$ $95 \% \mathrm{CI}=1.16-0.64)$ and severe $(\mathrm{OR}=0.37,95 \% \mathrm{CI}=0.16$ - 0.89) types. Also, based on logistic regression test, the only risk factor for severe type compared with mild type of preeclampsia was $\mathrm{BMI}(\mathrm{OR}=1.20,95 \% \mathrm{CI}=1.03-1.68)$.

\section{Discussion}

During the past two decades, little has been known about risk factors of preeclampsia and its severity and the limited existing information has suggested various patterns of risk factors for different types of preeclampsia. The findings of this study indicated that chronic hypertension is considered as the most powerful risk factor for the development of preeclampsia. However, based on the results of the logistic regression analysis, it seems chronic hypertension be a risk factor only for the mild type of this disease.

Catov and colleagues reported that chronic hypertension could increase the risk of severe preeclampsia up to $16.7 \%$ for the nullipara and $9.8 \%$ for the multipara. The risk of developing severe preeclampsia was $(\mathrm{OR}=6.2$ and $\mathrm{CI}=$ 4.2 - 9.1) for nullipara and $(\mathrm{OR}=3.0$ and $\mathrm{CI}=1.4$ - 6.4) multipara. One of the diagnostic criteria of severe preeclampsia in Catov's study was, while in this study criteria was. What makes this difference was the different norm of severity rating [11].

Luealon [12] also confirmed the importance of chronic hypertension as a major risk factor for preeclampsia; however his analysis was not based on severity. One explanation for this relation is that endothelial dysfunction plays an important role in pathogenesis of both of them [13]. Yet, in a study carried out by Kashanian and colleagues, chronic hypertension was considered as a cause of increase in the risk of preeclampsia which was not statistically significant [14]. The relation between $\mathrm{RH}$ factor and preeclampsia was another finding of this study, whereas no significant re- 
Table 1. Distribution of Basic Characteristics of the Study Population ${ }^{\mathrm{a}}$

\begin{tabular}{|c|c|c|c|c|c|c|}
\hline Variables & Healthy Pregnant, $N=330$ & Mild Preeclampsia, $\mathbf{N}=77$ & $\begin{array}{l}\text { Severe Preeclampsia, } \mathrm{N}= \\
91\end{array}$ & PValue $^{\mathbf{b}}$ & PValue $^{c}$ & PValue $^{\text {d }}$ \\
\hline $\operatorname{Age}^{b}, y$ & $27.93 \pm 5.83$ & $29.03 \pm 6.24$ & $30.07 \pm 6.22$ & 0.008 & 0.14 & 0.003 \\
\hline Lodging & $175(53.0)$ & $38(52.8)$ & $43(50.6)$ & 0.922 & 0.96 & 0.68 \\
\hline \multicolumn{7}{|l|}{ City } \\
\hline Village & $155(47.0)$ & $34(47.2)$ & $42(49.4)$ & & & \\
\hline missing & 0 & 5 & 6 & & & \\
\hline Employment & & & & 0.059 & 0.23 & 0.065 \\
\hline Housekeeper & $318(96.4)$ & $70(93.3)$ & $91(100)$ & & & \\
\hline Employed & $12(3.6)$ & $5(6.7)$ & $0(0.0)$ & & & \\
\hline missing & 0 & 2 & 0 & & & \\
\hline BMI $^{\mathbf{b}}$ & $25.91 \pm 5.9$ & $28.99 \pm 6.1$ & $26.29 \pm 4.77$ & 0.001 & 0.007 & 0.84 \\
\hline Parity & & & & 0.146 & 0.18 & 0.093 \\
\hline Multi parity & $156(47.3)$ & $30(39.0)$ & $34(37.4)$ & & & \\
\hline Null parity & $174(52.7)$ & $47(61.0)$ & $57(62.6)$ & & & \\
\hline \multicolumn{7}{|l|}{ Blood group } \\
\hline \multicolumn{7}{|l|}{ A } \\
\hline в & $84(26.2)$ & $25(33.3)$ & $26(29.9)$ & & & \\
\hline $\mathbf{A B}$ & $94(29.4)$ & $17(22.7)$ & $20(23.0)$ & 0.271 & 0.14 & 0.26 \\
\hline o & $20(6.2)$ & $9(12.0)$ & $10(11.5)$ & & & \\
\hline \multirow[t]{2}{*}{ missing } & $122(38.1)$ & $24(32.0)$ & $31(35.6)$ & & & \\
\hline & 10 & 2 & 4 & & & \\
\hline $\mathbf{R h}$ & & & & 0.001 & 0.001 & 0.001 \\
\hline Positive & $267(83.4)$ & $33(44.0)$ & $40(46.0)$ & & & \\
\hline Negative & $53(16.6)$ & $42(56.0)$ & $47(54.0)$ & & & \\
\hline Missing & 10 & 2 & 4 & & & \\
\hline Consanguinity & $24(7.3)$ & $4(5.2)$ & $6(6.6)$ & 0.805 & 0.52 & 0.82 \\
\hline \multicolumn{7}{|l|}{ Number of marriages } \\
\hline \multicolumn{7}{|l|}{ First marriage } \\
\hline \multirow[t]{2}{*}{ Second marriages } & $318(96.4)$ & $76(98.7)$ & $90(98.9)$ & & & \\
\hline & $12(3.6)$ & $1(1.3)$ & $1(1.1)$ & 0.295 & 0.65 & 0.50 \\
\hline Prior to birth spacing ${ }^{b}$ & $3.28 \pm 4.5$ & $3.75 \pm 5.02$ & $3.59 \pm 5.1$ & 0.94 & 0.43 & 0.57 \\
\hline Abortion & $55(16.7)$ & $23(29.9)$ & $22(24.2)$ & 0.019 & 0.008 & 0.10 \\
\hline History of preeclampsia & $33(10.0)$ & $19(24.7)$ & $18(19.8)$ & 0.001 & 0.001 & 0.011 \\
\hline $\begin{array}{l}\text { The current twin } \\
\text { pregnancy }\end{array}$ & $15(4.5)$ & $7(9.1)$ & $9(9.9)$ & 0.092 & 0.001 & 0.052 \\
\hline \multicolumn{7}{|l|}{ Sex } \\
\hline Boy & $173(53.1)$ & $36(46.8)$ & $52(57.1)$ & 0.401 & 0.37 & 0.45 \\
\hline Girl & $153(46.9)$ & $41(53.2)$ & $39(42.9)$ & & & \\
\hline missing & 4 & 0 & 0 & & & \\
\hline Diabetes & $51(15.5)$ & $19(24.7)$ & $15(16.5)$ & 0.151 & 0.054 & 0.81 \\
\hline Chronic hypertension & $7(2.1)$ & $10(13.0)$ & $9(9.9)$ & 0.001 & 0.001 & 0.001 \\
\hline Migraine & $12(3.7)$ & $4(5.2)$ & $9(9.9)$ & 0.055 & 0.53 & 0.026 \\
\hline Urinary Tract Infection & $78(23.6)$ & $25(32.9)$ & $26(28.6)$ & 0.207 & 0.094 & 0.33 \\
\hline
\end{tabular}

${ }^{a}$ Value are expressed as No. (\%).

b ANOVA (Post Hoc); For other comparisons used chi-square test; Comparison between healthy pregnant and mild preeclampsia.

${ }^{c}$ Comparison between mild preeclampsia and severe preeclampsia.

${ }^{\mathrm{d}}$ Comparison between healthy pregnant and severe preeclampsia.

lationship between $\mathrm{ABO}$ blood groups and mild or severe preeclampsia was observed.

In one study by Mahaba and colleges, the incidence of developing preeclampsia in $\mathrm{RH}$ negative women was higher than RH positive ones which were similar with our results [15]. However, Lee et al. observed that the risk of developing preeclampsia in $\mathrm{RH}$ positive women was a little higher than $\mathrm{RH}$ negatives. $(\mathrm{OR}=1.07,95 \% \mathrm{CI}=1.03-1.10)$ [16]. 
Table 2. Estimated Adjusted Odds Ratio for the Variable Preeclampsia (Mild and Severe) Compared with Healthy Pregnant Women ${ }^{a}$

\begin{tabular}{lccc}
\hline Variable & $($ OR $)$ & CI (\%95) & P Value \\
\hline hypertension & 12.33 & $(1.99-76.05)$ & 0.007 \\
Negative Rh & 6.99 & $(3.43-14.24)$ & 0.001 \\
History of preeclampsia & 3.22 & $(1.23-8.46)$ & 0.017 \\
BMI & 1.09 & $(1.02-1.17)$ & 0.007 \\
\hline${ }^{a}$ Logistic regression model. & & &
\end{tabular}

Table 3. Estimated Adjusted Odds Ratio for the Variable Mild Preeclampsia Compared with Healthy Pregnant Women ${ }^{\mathrm{a}}$

\begin{tabular}{lccc}
\hline Variable & $(\mathrm{OR})$ & CI (\%95) & P Value \\
\hline BMI & 1.09 & $(1.04-1.14)$ & 0.001 \\
Negative Rh & 7.94 & $(4.18-15.11)$ & 0.001 \\
\hline Multi parity & 0.32 & $(0.16-0.64)$ & 0.001 \\
\hline abortion & 2.72 & $(1.33-1.56)$ & 0.006 \\
History of preeclampsia & 3.93 & $(1.69-9.14)$ & 0.001 \\
Chronic hypertension & 13.7 & $(3.6-52.14)$ & 0.001 \\
\hline
\end{tabular}

${ }^{a}$ Logistic regression model.

Table 4. Estimated Adjusted Odds Ratio for the Variable Severe Preeclampsia Compared with Healthy Pregnant Women ${ }^{\mathrm{a}}$

\begin{tabular}{lccc}
\hline Variable & $(\mathrm{OR})$ & CI (\%95) & P Value \\
\hline Negative Rh & 5.14 & $(2.4-11.07)$ & 0.001 \\
Multi parity & 0.37 & $(0.16-0.89)$ & 0.03 \\
History of preeclampsia & 4.2 & $(1.58-11.3)$ & 0.004 \\
\hline
\end{tabular}

${ }^{\mathrm{a}}$ Logistic regression model.

According to results, it seems that the relation between $\mathrm{RH}$ and preeclampsia has been occurred as a result of immunological maladaptation hypothesis of mother and fetus.

Previous studies have shown positive history of preeclampsia as a valuable clinical indicator to determine the risk of preeclampsia during pregnancy [12,16,17].

The reported risk of developing preeclampsia in Luealon et al. was (OR=17.0, 95\% CI=3.3-87.6) [12] and in González et al. [18] was ( $\mathrm{OR}=23.7)$ also, in our study, the history of preeclampsia increased the risk of developing mild ( $\mathrm{OR}=3.9395 \% \mathrm{CI}=1.69$ - 9.14) and severe types ( $\mathrm{OR}=$ $4.295 \% \mathrm{CI}=1.58$ - 11.3). Garovic and colleagues supported the association between preeclampsia and the future development of hypertension and coronary heart diseases by metabolic and vascular abnormalities which could be a probable explanation for this disorder [13].

In this study, there was a positive association between pre-pregnancy BMI and risk of preeclampsia which was similar with Odegard and colleagues which demonstrated that increased weight was more associated with the mild preeclampsia [19] and the same result was reinforced by Sohlberg et al. [20].

In previous studies, types of abortion(induced vs. spontaneous), number of abortion (two induced abortion or more vs. one abortion), gestational age at the time of abortion(over 13 weeks vs under 13 weeks) could significantly increase the protection rate and new sexual partner could decrease it [6].

One limitation of our study was a part of our data collection extract from medical records of patients.

Although, another noticeable fact in this study was the effect of history of abortion on increasing risk of mild preeclampsia $(\mathrm{OR}=2.72,95 \% \mathrm{CI}=1.33-5.56)$. However, in a review, done by Trogstad et al. it was indicated as a protecting factor in the following pregnancies [6].

since mother's clinical features are mostly used in prediction of preeclampsia because of limited diagnostic instruments and lack of easier and more convenient methods to detect, it is strongly recommended that the risk factors of this disorder and its severity by further investigations to develop new models for its prediction.

\subsection{Conclusion}

Based on results, chronic hypertension, history of abortion and BMI had been indicated as risk factors of mild preeclampsia and history of preeclampsia had been obtained as the risk factors of severe type. Also, negative RH was the common risk factor for mild and severe types. Therefore, our result supported different risk factors of preeclampsia.

\section{Acknowledgments}

This paper used data from a thesis (No. 1505). The authors thank Guilan University of Medical Sciences who supported us in this study.

\section{Footnotes}

Authors' Contribution: All authors had equal role in design, work, statistical analysis and manuscript writing.

Conflict of interest: None declared. 


\section{References}

1. Redman CW, Sargent IL. Latest advances in understanding preeclampsia. Science. 2005;308(5728):1592-4. doi: 10.1126/science.1111726. [PubMed: 15947178].

2. Reyes LM, Garcia RG, Ruiz SL, Camacho PA, Ospina MB, Aroca G, et al. Risk factors for preeclampsia in women from Colombia: a case-control study. PLoS One. 2012;7(7):e41622. doi: 10.1371/journal.pone.0041622. [PubMed: 22911827].

3. Bahadoran P, Zendehdel M, Movahedian A, Zahraee RH. The relationship between serum zinc level and preeclampsia. Iran J Nurs Midwifery Res. 2010;15(3):120-4. [PubMed: 21589774].

4. Savaj S, Vaziri N. An overview of recent advances in pathogenesis and diagnosis of preeclampsia. Iran J Kidney Dis. 2012;6(5):334-8. [PubMed: 22976257].

5. Baker AM, Klein RL, Moss KL, Haeri S, Boggess K. Maternal serum dyslipidemia occurs early in pregnancy in women with mild but not severe preeclampsia. Am J Obstet Gynecol. 2009;201(3):1-4. doi: 10.1016/j.ajog.2009.05.037. [PubMed: 19631926].

6. Trogstad L, Magnus P, Stoltenberg C. Pre-eclampsia: Risk factors and causal models. Best Pract Res Clin Obstet Gynaecol. 2011;25(3):329-42. doi: 10.1016/j.bpobgyn.2011.01.007. [PubMed: 21349772].

7. Duckitt K, Harrington D. Risk factors for pre-eclampsia at antenatal booking: systematic review of controlled studies. BMJ. 2005;330(7491):565. doi: 10.1136/bmj.38380.674340.E0. [PubMed: 15743856].

8. Khalil MM, Alzahra E. Fetal gender and pregnancy outcomes in Libya: a retrospective study. Libyan J Med. 2013;8 doi: 10.3402/ljm.v8i0.20008.

9. Facchinetti F, Allais G, D'Amico R, Benedetto C, Volpe A. The relationship between headache and preeclampsia: a case-control study. Eur J Obstet Gynecol Reprod Biol. 2005;121(2):143-8. doi: 10.1016/j.ejogrb.2004.12.020. [PubMed:16054953].

10. Alpoim PN, de Barros Pinheiro M, Junqueira DRG, Freitas LG, das Graças Carvalho M, Fernandes APSM, et al. Preeclampsia and ABO blood groups: a systematic review and meta-analysis. MolBiol Rep. 2012;40(3):2253-61. doi: 10.1007/s11033-012-2288-2.

11. Catov JM, Ness RB, Kip KE, Olsen J. Risk of early or severe pre-eclampsia related to pre-existing conditions. Int J Epidemiol. 2007;36(2):412-9. doi: 10.1093/ije/dyl271. [PubMed: 17255351].

12. Luealon P, Phupong V. Risk factors of preeclampsia in Thai women.J Med Assoc Thai. 2010;93(6):661-6. [PubMed: 20572370].

13. Garovic VD, August P. Preeclampsia and the future risk of hypertension: the pregnant evidence. Curr Hypertens Rep. 2013;15(2):114-21. doi: 10.1007/s11906-013-0329-4. [PubMed: 23397213].

14. Kashanian M, Baradaran HR, Bahasadri S, Alimohammadi R. Risk factors for pre-eclampsia: a study in Tehran, Iran. Arch Iran Med. 2011;14(6):412-5. [PubMed: 22039846].

15. Mahaba HM, Ismail NA, El Damaty SI, Kamel HA. Pre-eclampsia: epidemiology and outcome of 995 cases. J Egypt Public Health Assoc. 2001;76(5-6):357-68. [PubMed: 17216932].

16. Lee BK, Zhang Z, Wikman A, Lindqvist PG, Reilly M. ABO and RhD blood groups and gestational hypertensive disorders: a populationbased cohort study. BJOG. 2012;119(10):1232-7. doi: 10.1111/j.14710528.2012.03421.x. [PubMed: 22734590].

17. Merviel P, Touzart L, Deslandes V, Delmas M, Coicaud M, Gondry J. [Risk factors of preeclampsia in single pregnancy]. J Gynecol Obstet Biol Reprod (Paris). 2008;37(5):477-82. doi: 10.1016/j.jgyn.2008.04.001. [PubMed: 18501532].

18. Gonzalez AL, Ulloa Galvan G, Alpuche G, Romero Arauz JF. [Risk factors for preeclampsia. Multivariate analysis]. Ginecol Obstet Mex. 2000;68:357-62. [PubMed: 11055112].

19. Odegard RA, Vatten LJ, Nilsen ST, Salvesen KA, Austgulen R. Risk factors and clinical manifestations of pre-eclampsia. BJOG. 2000;107(11):14106. [PubMed: 11117771].

20. Sohlberg S, Stephansson O, Cnattingius S, Wikstrom AK. Maternal body mass index, height, and risks of preeclampsia. Am J Hypertens. 2012;25(1):120-5. doi:10.1038/ajh.2011.175. [PubMed: 21976280]. 